\title{
Supporting student quantitative skills across introductory STEM courses: faculty approaches and perceived needs
}

\author{
Melissa Eblen-Zayas and Ellen Altermatt \\ Carleton College, $1 \mathrm{~N}$ College St, Northfield, MN, 55057 \\ Laura J. Muller and Jonathan Leamon \\ Williams College, 880 Main Street, Williamstown, MA, 01267 \\ Sundi Richard \\ Davidson College, 405 N Main Street, Davidson, NC, 28035
}

\begin{abstract}
We present the results of a survey of 220 faculty members at selective liberal arts colleges who teach introductory STEM courses. The survey was designed to learn how these faculty support student quantitative skills development in their introductory courses and what high-school-level quantitative skills are the most challenging for their incoming introductory students. In particular, we wanted to identify the skills that students struggled with across different disciplines in order to explore collaborative development of shared online modules to support student quantitative skills review and practice in many different introductory STEM courses. Five priority topic areas emerged - graphs and tables, descriptive statistics, exponents/logarithms, intercepts/slopes of lines, and confidence intervals/standard error - although there were significant disciplinary differences.
\end{abstract}




\section{INTRODUCTION}

College and university faculty are faced with the dual problem of supporting students with less preparation or confidence in high-school-level math skills and linking math concepts to their courses to support quantitative skills (QS) in their disciplines. As students arrive at college with a broader range of math backgrounds and need to use QS more frequently across the curriculum [1,2], helping faculty meet this challenge becomes pressing. Two primary approaches have been developed to address this challenge: 1) construction of interdisciplinary courses or curricula and 2) embedding skills development modules within existing subjects. Constructing new curricula requires major curricular overhaul and is not portable from situation to situation. Embedded QS development can take a variety of forms, but online modules are of particular interest because of the possibility for selfpaced engagement and portability. Embedded math skills development with online materials can use either commercially available materials (e.g. ALEKS [3], MyMathTest [4]) or faculty-developed modules (e.g. The Math You Need When You Need It [5, 6], MathBench [7]). Students benefit from both commercial online materials [8,9] and facultydeveloped modules [10-13].

Most existing modules focus on skill development for a particular disciplinary context. Although using familiar examples can provide benefits for student learning, such use of concrete, specific examples can hinder learners' ability to recognize and transfer their knowledge to new analogous situations [14]. Therefore, modules that review quantitative skills and provide examples of the usage of those skills in a number of different disciplinary contexts have the potential to help foster transfer of skills across different disciplinary contexts. In particular, less than $3 \%$ of students taking an introductory physics course major in physics [15]; therefore, developing online modules for review of quantitative skills that show the relevance of those skills to a variety of different disciplines would likely engage students with diverse areas of interest more than modules that are solely focused on developing quantitative skills in a physics context.

At small liberal arts colleges, faculty often express a commitment to supporting student success through close personal interactions. We wanted to understand how faculty in these contexts currently support student quantitative skill review and practice and where there are common concerns about students' quantitative skills across multiple disciplines. Ultimately, our interest is in collaborative development and adoption of online modules to provide support for quantitative skills across introductory courses in a variety of disciplines. These modules will support students in understanding how to use quantitative skills in different disciplinary contexts. Although the existing literature shows there are interdisciplinary programs or courses to support students in building quantitative skills [16, 17], we are not familiar with any existing online modules for supporting quantitative skills that are designed to demonstrate the relevance of particular skills across disparate disciplines.

We surveyed faculty at the 10 liberal arts colleges that comprise the Liberal Arts Collaborative for Digital Innovation (LACOL) to identify approaches faculty are already using to support the development of student quantitative skills in their introductory science and social courses, and to solicit feedback on the most pressing topics where additional support is needed. The results provide a snapshot of the approaches faculty at this group of selective liberal arts colleges take in order to support the development of students' quantitative skills, as well as identifying the common quantitative skills topics across disciplines where faculty think students could benefit from additional review and practice.

\section{SURVEY CONTEXT}

LACOL was founded in 2014 as a partnership of leading liberal arts institutions to explore online pedagogies and support for effective teaching and learning in residential settings. The consortium currently consists of ten institutions (Amherst, Bryn Mawr, Carleton, Davidson, Hamilton, Haverford, Swarthmore, Vassar, Washington and Lee, Williams). Traditionally in these small, residential liberal arts colleges, faculty have tended to offer personalized one-on-one support for struggling students. There are several limitations to this approach: 1) This is time-consuming for faculty; 2) Students from some demographic groups are reluctant to come to faculty to seek help [18-20]; 3) Faculty often work on triaging skills needed for the immediate moment, but do not think about how to support student QS development and selfefficacy more broadly. Online modules for just-in-time QS support would be an appropriate supplement to personalized support, and our survey was designed to understand both how faculty currently support the development of quantitative skills in students enrolled in their introductory courses and to solicit feedback on what quantitative skills topics are of interest to faculty across disciplines.

Five hundred forty faculty members at the 10 LACOL institutions, who had either taught introductory courses with a quantitative skills component in 2018-2019 or who expected to teach those courses in the 2019-2020 academic year were invited to respond to respond to the survey, and 220 faculty members $(40.7 \%)$ responded. The faculty represented a broad cross-section of STEM disciplines (shown in Fig. 1), which is important to developing modules that will address topics that are relevant to multiple disciplines, thereby fostering opportunities to transfer skills across disciplinary contexts.

\section{SURVEY AND RESULTS}

Faculty were asked to indicate what resources they currently use to support the development of quantitative skills in students in their introductory courses (Fig. 2). From a list of eight approaches for supporting quantitative skills that 
$\begin{array}{lllllllll}0 & 5 & 10 & 15 & 20 & 25 & 30 & 35 & 40\end{array}$

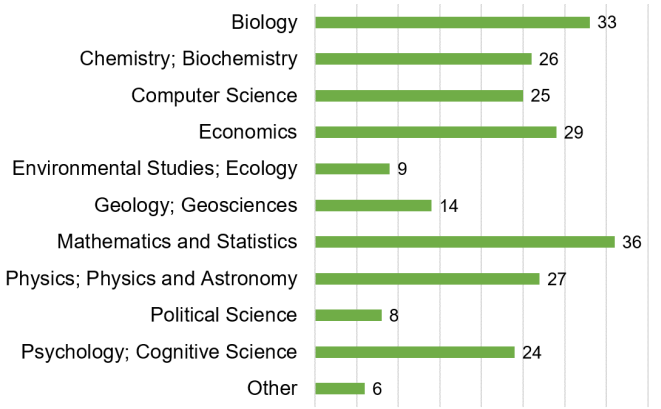

FIG. 1. Number of faculty survey respondents by discipline. Faculty teaching in two different disciplines are counted in both disciplines.

we had heard faculty discuss, survey respondents could select as many approaches as applied to their situation. The most common support approach was out-of-class meetings with individual students, an approach employed by $82 \%$ of respondents. In addition, $59 \%$ of faculty spent additional class time reviewing quantitative skills in their introductory courses and $55 \%$ scheduled out-of-class meetings with groups of students. Faculty also referred students to other resources, with $69 \%$ referring students to peer tutors and $61 \%$ referring students to textbooks or textbook supplements. However, only $37 \%$ of faculty reported referring students to staff colleagues at campus support centers. Online resources for quantitative skill building and review have not been widely adopted by faculty at LACOL institutions, with only $44 \%$ of faculty reporting that they used online resources. Although the survey provided information on the support that faculty make available to students, this self-reported data cannot provide information about the actual effectiveness of various support approaches.

The open-ended responses to questions about how well support strategies were meeting faculty and student needs suggested that faculty do see benefits to online resources, particularly the flexibility that these resources provide in allowing students to access and revisit these resources at any time. "Online resources are particularly valuable because they can be used whenever the student needs help" noted one faculty member. Another wrote that online resources provide "the ability to explore more easily on one's own time. Many of the aforementioned resources require an appointment." Consistent with these responses, among participants who reported that they were not currently using online resources to support the development of quantitative skills in introductory courses, the majority $(80 \%)$ indicated that they would be interested in using these resources.

Faculty respondents who were currently using online resources or who expressed an interest in using online resources were asked to indicate up to three topics for which they would be most interested in using online resources from a list of 15 topics. Although topic areas were derived from the empirical literature, from existing online resources developed for spe- $\begin{array}{llllll}0 \% & 20 \% & 40 \% & 60 \% & 80 \% & 100 \%\end{array}$

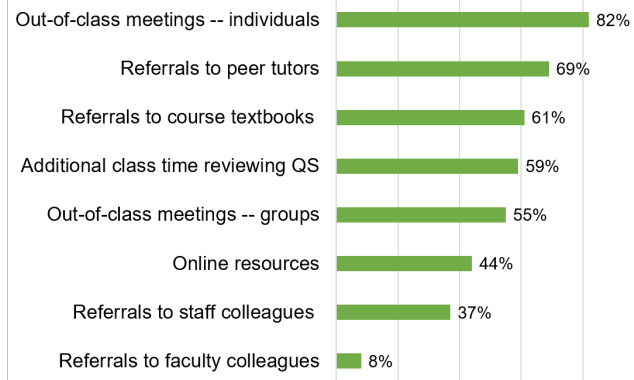

FIG. 2. Percentage of faculty survey respondents who report using each of eight different approaches to supporting student quantitative skills.

cific disciplines, and from state standards for mathematics, LACOL consortium-wide conversations dating back to 2016 as well as conversations on individual campuses informed the selection of the topics listed on the survey. The 15 topics areas were: algorithms, confidence intervals/standard error, descriptive statistics (e.g. mean, mode, median, standard deviation, percentile rank), exponents/logarithms, factoring and simplifying algebraic expressions, geometry, graphs and tables (e.g. constructing, reading, and interpreting), intercepts and slopes of lines, percentages/percent change, probability, random sampling/assignment, rates, trigonometry, and units and unit conversion.

Of the 111 faculty members who indicated interest in online resources and responded to the question about topical focus for modules, $25 \%$ or more of faculty respondents expressed interest in using online resources to build quantitative skills in five "priority" topic areas: graphs and tables $(56 \%)$, descriptive statistics (36\%), exponents/logarithms $(28 \%)$, intercepts/slopes of lines $(26 \%)$, and confidence intervals/standard error (25\%). Although there were substantial disciplinary differences in the topic areas that garnered the most interest, at least one of the top three priority topics for the sample as a whole (i.e., graphs and tables, descriptive statistics, and exponents/logarithms) was selected by $25 \%$ or more of faculty who taught courses in each of the 9 academic disciplines included in the sample (Fig. 3). Specifically, graphs and tables was selected as a priority topic by more than $25 \%$ of faculty in 8 disciplines and descriptive statistics and exponents/logarithms were both selected as priority topics by more than $25 \%$ of faculty in 5 disciplines. Fig. 4 shows the top three priority quantitative skills topics selected for module development by faculty in each discipline. Among the physics faculty members who responded $(n=21)$, the five priority topic areas were: trigonometry (62\%), graphs and table (57\%), fractions and proportional reasoning (52\%), factoring and simplifying algebraic expression (48\%), and exponents/logarithms (38\%).

To better understand how faculty members conceptualize the quantitative skills that they selected as priority topics, survey respondents were asked to give examples of the ways that 


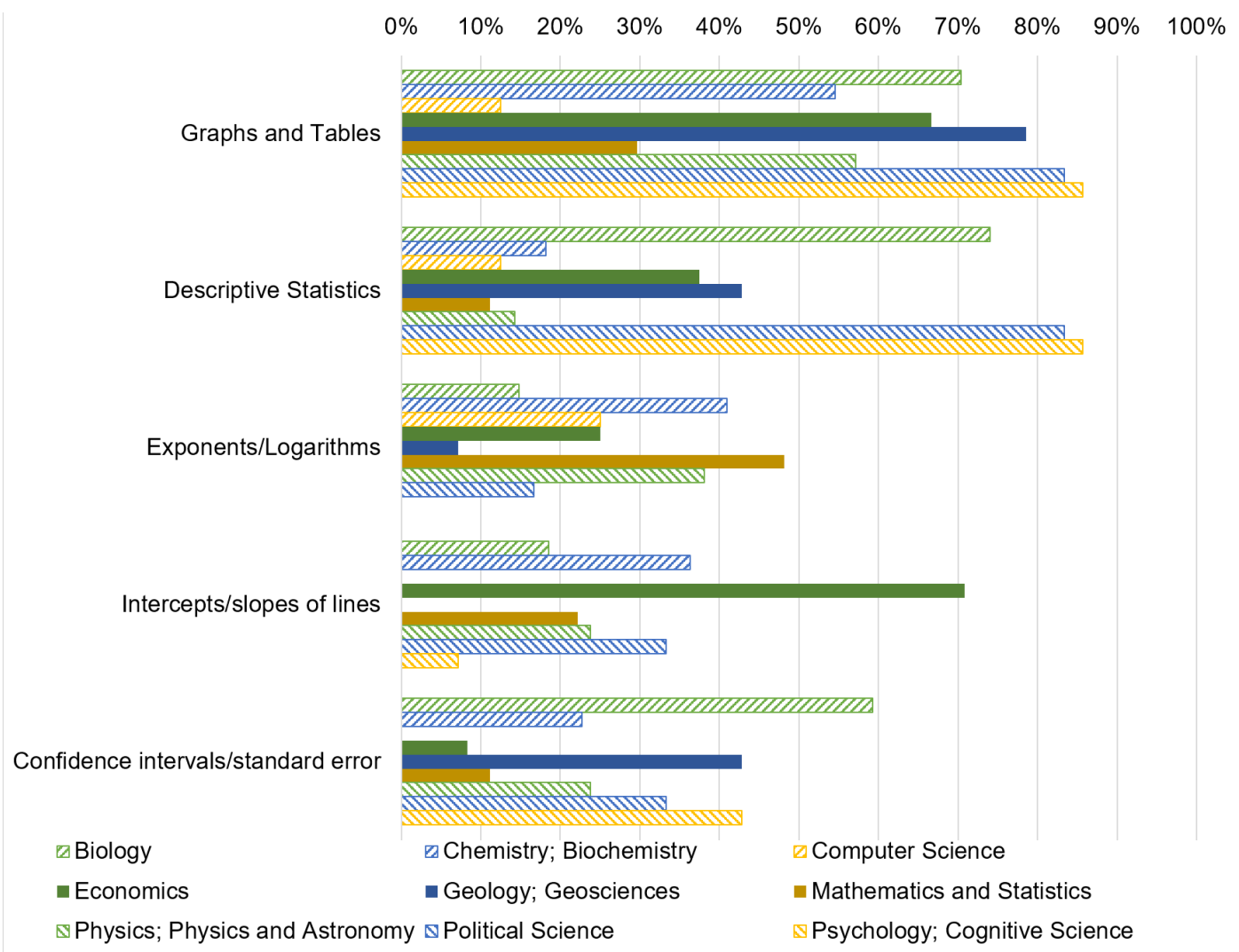

FIG. 3. Percent of faculty in each discipline who selected each of the top five priority topics as among the top three for which they would be interested in using online resources.

students were expected to demonstrate these skills in their course(s). These open-ended responses allowed us to identify common ways that faculty expected students to use the skills across different disciplines.

\section{USING SURVEY RESULTS}

The survey results are serving as the foundation for collaboratively developing online modules on the high priority topics identified. Each module will include instructional materials that review one of the skills in a general context, and then each module will provide opportunities for students to practice using the skill in multiple different disciplinary contexts, with automated feedback on student work. The goal is that each module will be able to provide students from introductory courses in multiple disciplines with targeted practice and review of the selected quantitative skill.

We are engaging faculty at the LACOL institutions in an iterative dialogue process, which is still underway, that is designed to help identify the appropriate scope of the online modules. Workshops with faculty stakeholders from multiple disciplines have provided opportunities for faculty to better understand how the language describing and usage of key quantitative skills varies from one introductory course to an- other, and what are the commonalities in terms of perceived needs for additional support for students. For example, the open-ended survey responses about the logarithms/exponents topic suggested that faculty were interested in strengthening student understanding of several larger conceptual ideas such as the relationship between exponential and logarithmic functions and how logarithmic and exponential functions help scientists work with large numbers and put them into context. However, during the in-person workshops, faculty also identified common skills that they hoped the module would help students practice such as manipulating algebraic expressions that involve exponents and logarithms, interpreting graphs involving exponential or logarithmic functions, and working with examples that demonstrate the types of real-world systems that are modeled by exponential and logarithmic functions. Workshop conversations with faculty across different disciplines and different LACOL institutions refined our understanding of the types of skills that faculty think students most need to review and practice beyond the limits of what we could learn from the survey.

Additionally, faculty partners are providing input on how to highlight the relevance of a particular QS in their disciplines so as to create a module that can be used by faculty in multiple disciplines and demonstrate to students the transferability of the skill to multiple contexts. We have shown 


\begin{tabular}{|c|c|}
\hline $\begin{array}{c}\text { Discipline } \\
\text { (\# of respondents) }\end{array}$ & $\begin{array}{l}\text { Top three topics for modules } \\
\text { (\# and \% of faculty respondents) }\end{array}$ \\
\hline $\begin{array}{l}\text { Biology } \\
(n=27)\end{array}$ & 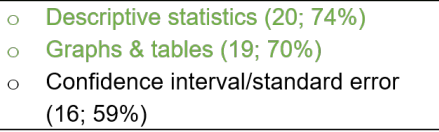 \\
\hline $\begin{array}{l}\text { Chemistry/ } \\
\text { Biochemistry } \\
(\mathrm{n}=22)\end{array}$ & $\begin{array}{ll} & \text { Units \& unit conversion }(17 ; 77 \%) \\
& \text { Graphs \& tables }(12 ; 55 \%) \\
& \text { Fractions \& proportional reasoning } \\
& (10 ; 45 \%) \\
\end{array}$ \\
\hline $\begin{array}{l}\text { Computer Science } \\
(n=16)\end{array}$ & $\begin{array}{ll} & \text { Algorithms (15, 94\%) } \\
\text { Exponents/logarithms (4; 25\%) } \\
\text { Descriptive statistics }(2 ; 13 \%) \text { and } \\
\text { Graphs \& tables }(2,13 \%)\end{array}$ \\
\hline $\begin{array}{l}\text { Economics } \\
(\mathrm{n}=24)\end{array}$ & $\begin{array}{ll} & \text { Intercepts \& slopes of lines }(17 ; 71 \%) \\
& \text { Graphs \& tables }(16 ; 67 \%) \\
& \text { Percent/percent change }(11 ; 46 \%)\end{array}$ \\
\hline $\begin{array}{l}\text { Geology; } \\
\text { Geosciences } \\
(n=14)\end{array}$ & $\begin{array}{ll} & \text { Graphs \& tables }(11 ; 79 \%) \\
0 & \text { Units \& unit conversion }(7 ; 50 \%) \\
& \text { Confidence intervals/standard error } \\
& (6 ; 43 \%) \\
\end{array}$ \\
\hline $\begin{array}{l}\text { Mathematics and } \\
\text { Statistics } \\
(n=27)\end{array}$ & $\begin{array}{ll} & \text { Trigonometry }(14 ; 52 \%) \\
& \text { Exponents/logarithms (13; 48\%) } \\
& \text { Factoring \& simplifying algebraic } \\
& \text { expressions }(10 ; 37 \%) \\
\end{array}$ \\
\hline $\begin{array}{l}\text { Physics; Physics } \\
\text { and Astronomy } \\
(\mathrm{n}=21)\end{array}$ & $\begin{array}{ll} & \text { Trigonometry }(13 ; 62 \%) \\
& \text { Graphs \& tables }(12 ; 57 \%) \\
& \text { Fractions \& proportional reasoning } \\
& (11 ; 52 \%)\end{array}$ \\
\hline
\end{tabular}

FIG. 4. Top three topics for module development by discipline, based on responses of faculty who indicated an interest in using online resources $(n=111)$. Colored text indicates which of the disciplinary priority topics were also overall priority topics.

them both commercially available and NSF-supported materials for discussion of applicability, scope, and range of topics with respect to their courses. With their permission, we are using faculty workshop participant examples and feedback in our module development process.

\section{CONCLUSIONS}

Although online modules have been shown to support student quantitative skills development, survey results indicate that faculty at selective liberal arts colleges primarily focus on one-on-one support during office hours to help students who are struggling with quantitative skills in introductory STEM courses. Only $44 \%$ of faculty have used online modules, but faculty see the benefits of online modules for student support, in particular the ability for students to access the modules at any time and to practice and get immediate feedback.

At liberal arts colleges, where many students enrolled in introductory STEM courses may not major in that field, creating modules that will help students strengthen their quantitative skills while seeing the relevance of those skills to multiple disciplines is important. Through the survey, we identified five quantitative skills topics that were of interest to faculty across different disciplines - graphs and tables, descriptive statistics, exponents/logarithms, intercepts/slopes of lines, and confidence intervals/standard error.

Dialogues with faculty partners will allow us to define the scope of online modules that could support opportunities for students to strengthen and transfer QS for multiple introductory STEM courses. In the future, we will explore how disciplinary and institutional context, as well as level of involvement in the dialogue process around module development, impacts faculty choices about whether to use the modules and their potential usefulness as one approach to supporting student quantitative skills across the curriculum.

\section{ACKNOWLEDGMENTS}

This work is supported by the National Science Foundation Division of Undergraduate Education under Grant No. 1829135 .
[1] S.L. Ganter and W. Barker, eds. The Curriculum Foundations Project: Voices of the Partner Disciplines. Mathematical Association of America, Washington, DC. (2004).

[2] S.L. Ganter and W. E. Haver, eds. Partner discipline recommendations for introductory college mathematics and the implications for college algebra. Mathematical Association of America, Washington, DC. (2011).

[3] http://aleks.com. Retrieved 6/04/2020.

[4] https://www.pearsonmylabandmastering.com/northamerica/ mymathtest/. Retrieved 6/04/2020.

[5] https://serc.carleton.edu/mathyouneed/index.html. Retrieved $6 / 04 / 2020$.

[6] https://serc.carleton.edu/mathyouneedecon/index.html. Retrieved 6/04/2020.

[7] https://mathbench.umd.edu/. Retrieved 6/04/2020.

[8] D.C. Jackson and E.D. Johnson. International Journal of Mathematical Education in Science and Technology 44(6), 846
(2013). https://doi.org/10.1080/0020739X.2013.808769

[9] R.L. Forrest, D.W. Stokes, A.B. Burridge, and C.D. Voight. Physical Review - Physics Education Research 13(2), 020137 (2017). https://doi.org/10.1103/PhysRevPhysEducRes.13. 020137

[10] K.V. Thompson, K.C. Nelson, G. Marbach-Ad, M. Keller, and W.F. Fagan. CBE-Life Sciences Education 9(3), 277 (2010). https://doi.org/10.1187/cbe.10-03-0028

[11] J.M. Wenner, H.E. Burn, and E.M. Baer. Journal of College Science Teaching 41(1), 16 (2011).

[12] H.E. Burn, E. Baer, and J.M. Wenner. About Campus, 18(5), 22-25 (2013). https://doi.org/10.1002/abc.21134

[13] K. Hoffman, S. Leupen, K. Dowell, K. Kephart, and J. Leips. CBE life sciences education 15(2), ar14 (2016). https://doi.org/ 10.1187/cbe.15-09-0186

[14] S.B. Day, B.A. Motz, and R.L. Goldstone. Frontiers in Psychology 6, 1876 (2015). https://doi.org/10.3389/fpsyg.2015. 
01876

[15] R.C. Hilborn. APS News 6(2), (1997). https://www.aps. org/publications/apsnews/199702/education.cfm. Retrieved 6/04/2020.

[16] D.C. Jackson, E.D. Johnson, and T.M. Blanksby. International Journal of Mathematical Education in Science and Technology 22(1), 67 (2014).

[17] M.L. Greer. PRIMUS 29(9), 928 (2019). https://doi.org/10. $1080 / 10511970.2018 .1488782$
[18] Y.K. Kim and L.J. Sax. Research in Higher Education 50(5), 437 (2009). https://doi.org/10.1007/s11162-009-9127-x

[19] E.T. Pascarella, C.T. Pierson, G.C. Wolniak, and P.T. Terenzini. The Journal of Higher Education 75(3), 249 (2004). https://doi. org/10.1080/00221546.2004.11772256

[20] C.M. Steele. American psychologist 52(6), 613 (1997). https: //doi.org/10.1037/0003-066X.52.6.613 